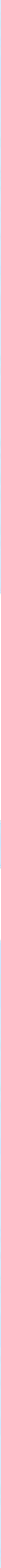


I. Crônicas

1. Crônicas da atualidade do Direito Internacional ......................................................16

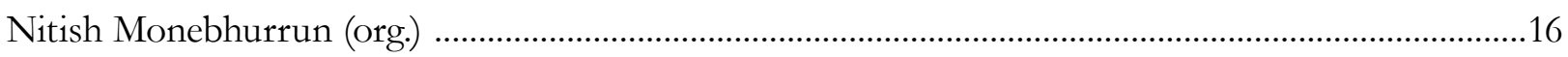

2.Decisões da Corte Internacional de Justiça e do Tribunal Internacional Sobre o Direito do Mar

Nitish Monebhurrun

José Eduardo Siqueira

3. Crônicas do direito internacional dos inVestimentos

Nitish Monebhurrun

\section{Os Vinte Anos dA OMC}

EXPORT CONTROLS AS INDUSTRIAL POLICY ON NATURAL RESOURCES: REGULATORY LIMITATIONS ON CHINA - RAW MATERIALS AND CHINA - RARE EARTHS CASES.

Gustavo Ferreira Ribeiro

O problema da espionagem econômica internacional: Seria a Organização Mundial do CoMÉRCIO O FORO ADEQUADO PARA SUA APRECIAÇÃO?

Humberto A.Vasconcelos Lima

Naiana Magrini Rodrigues Cunha

International Standards for Intellectual Property Rights Protection: a reflection on CLIMATE-FRIENDLY TECHNOLOGY TRANSFER.

Guihong Zhang

Jiani Jiang

Can Wang

Os vinte anos da OMC, suas conquistas e desafios: uma análise do Brasil e o Sistema de SoLUÇõES DE CONTROvÉRsias

Etiene M. Bosco Breviglieri

Luciano Meneguetti Pereira

A relação entre os tratados multilaterais ambientais e os acordos da OMC: é possível CONCILIAR O CONFLITO?

Fabio Costa Morosini,

Luisa Zuardi Niencheski 
Um desafio na Organização Mundial do Comércio: viabilidade de um aCordo Plurilateral

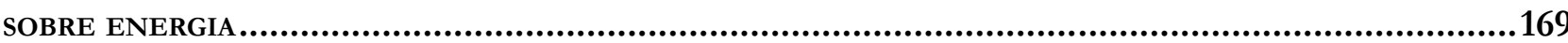

Matheus Linck Bassani

CONTRATAÇÕES PÚbliCAS NO ÂMBITO DA OMC: A POLÍTICA LEGISLATIVA BRASILEIRA À LUZ DO DIREITO AO DESENVOLVIMENTO

André Jansen do Nascimento

Governança global e a Organização Mundial do Comércio: desafios impostos pelo novo MANDATO DE DESENVOLVIMENTO

Letícia de Souza Daibert

Ana Luísa Soares Peres

Vinte Anos de Crise para a África? Poder, Assimetrias e a Abordagem Liberal da OMC.....239 Igor Abdalla Medina de Souza

Os MECANISMos DE INDUÇÃo AO CUMPRIMENTO NO ÂMBITO DA OMC .258

Fernando Lopes Ferraz Elias

A promoção de accountability na Organização Mundial do Comércio: uma anÁlise horiZONTAL E VERTICAI .280

Celso Henrique Cadete de Figueiredo

LA OMC Y EL PROCESO DE GLOBALIZACION DE LA REGULACIÓN ALIMENTARIA 307

Maria Eugenia Marichal

O ACORDO GATS E SUA APLICAÇÃo AOS SERVIÇOS DO COMÉRCIO ELETRÔNICO

Gleisse Ribeiro Alves

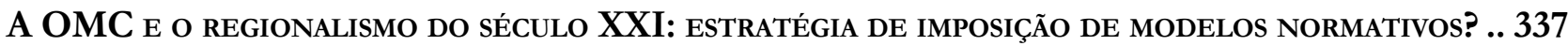
Camilla Capucio

A ORganizaÇão MUNDIAL do COMÉRCIO E A CHINA: DIREITO DE PROPRIEDADE E PROPRIEDADE INTELECTUAL NO PAÍs

Dos contenciosos na OMC COM ENFOQue Em Restrições Às EXPortações da China .363

Marco Antônio Alcântara Nascimento 
Alice Rocha da Silva

\section{Outros Temas}

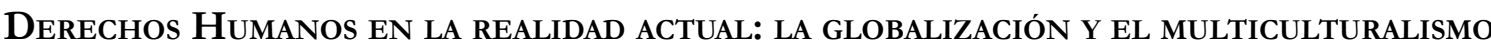

David Falcão

IMUNIDADE DE JURISDIÇÃo do EsTAdo E REPARAÇÃo CIVIL PELA PRÁtica de TORTURA: O CASO ZaHRA

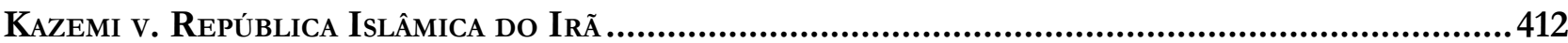

Patrícia Maria Lara Abreu

Rodrigo Otávio Bastos Silva Raposo

INTERREgIONAL ORgaNiZATIONS (IROS) IN EUROPE: NEW SUBJECTS OF CONTEMPORARY INTERNATIONAL LAW?

Davorin Lapas

A CONEXÃo ENTRE OS DIREITOS HUMANOS E A CORRUPÇÃo

Gabriela Alves Mendes Vieira

Marcelo Dias Varella

GRUPO DE SOCIEDADES: INSTRUMENTO JURÍDICO DE ORGANIZAÇÃO DA EMPRESA PLURISSOCIETÁRIA.....495

Daniel Amin Ferraz 


\title{
A OMC e o regionalismo do século XXI: estratégia de imposição de modelos normativos?*
}

\author{
WTO and regionalism in the $21^{\text {st }}$ century: strategy to \\ impose normative models?
}

Camilla Capucio**

\section{Resumo}

O objetivo central do artigo é recontextualizar a temática do regionalismo em sua relação com o sistema multilateral de comércio, passados vinte anos de criação da OMC. O trabalho se baseia numa nova geração de estudos, que identifica na proliferação de Acordos Regionais de Comércio pós-Rodada de Doha interesses diversos daqueles manifestados anteriormente, relacionados contemporaneamente à tentativa de imposição de um modelo regulatório-normativo, com futuros impactos na formulação de esquemas regulatórios globais. A metodologia consiste em análise bibliográfica da evolução do tratamento da temática pelas diversas gerações de estudiosos, em face das características peculiares do fenômeno em suas respectivas realidades, com destaque para essa nova "faceta". A conclusão central do trabalho, na qual subsiste seu principal valor, é a percepção de que, diante das novas complexidades do regionalismo no século XXI, iniciativas atuais buscam preencher o espaço de regulamentação de temas deixados pelo congelamento da Rodada de Doha. Conclui-se que a sistemática de negociação passa a circular não mais em função de barganhas para o acesso a mercados por meio de cortes tarifários, mas em torno da capacidade de expansão de modelos regulatórios, e que essa normatividade resultante dos novos acordos regionais tende a se cristalizar, exatamente devido à tipologia dos compromissos abarcados, que importam implicações jurídico-institucionais domésticas duradouras.

Palavras-chave: Acordos regionais de comércio. OMC. Sistema multilateral de comércio. Regionalismo. Multilateralismo.

\section{Abstract}

This paper is aimed to recontextualize the theme of regionalism in its relationship with the multilateral trading system, after twenty years of creation of the WTO.

* Recebido em 31.10.2014

Aceito em 01.12.2014

** Doutora em Direito Internacional (Faculdade de Direito da USP) e Mestre em Direito (Faculdade de Direito da UFMG). Pesquisadora do Núcleo de Estudos em Tribunais Internacionais (NETI-USP) e do Grupo de Pesquisa Empresa, Mercado e Desenvolvimento Social (UNA). Professora (Centro Universitário UNA).E-mail: ccapucio@usp.br
It is based on a new generation of studies, which identifies the proliferation of Regional Trade Agreements post-Doha Round with interests different from those expressed before, contemporaneously related to the attempt to impose a regulatory-normative model, with future impacts in formulating schemes of global regulation. The methodology consists on bibliographic analysis of the evolution of the treatment of the subject by several generations of scholars, in view of the peculiar characteristics of the phenomenon in their respective realities, especially in this new aspect. The central conclusion of the work, in which remains its main value, is the perception that, given the complexities of the new regionalism in the XXI century, current initiatives seek to fill the space left by the regulations of freezing issues in the Doha Round. The paper concludes that trade negotiation 
is focused no more in bargain for market access through tariff cuts, but mainly in the ability to expand regulatory models, and that the normativity that today seems diluted tends to crystallize.

Keywords: Regional trade agreements. WTO. Multilateral trading system. Regionalism. Multilateralism.

\section{Introdução: a OMC e o regionalismo}

A temática do regionalismo exige uma análise histórica do fenômeno, tendo em vista não apenas os diferentes aspectos que caracterizam as respectivas "ondas" do regionalismo observadas nas relações internacionais, mas principalmente as diversas perspectivas teóricas e pragmáticas construídas para entender as dimensões de sua relação com o Sistema Multilateral de Comércio.

Assim, diante de novas complexidades e novas características apresentadas pelo fenômeno do regionalismo no século XXI, é perceptível a insuficiência de análises clássicas limitadas à percepção de compatibilidades e/ou incompatibilidades estáticas dos Acordos Regionais de Comércio face ao sistema multilateral de comércio. Passados vinte anos de criação da OMC, é tarefa urgente recontextualizar a temática do regionalismo, tendo em vista a mudança de interesses buscados com a construção de arranjos regionais na atualidade, e os potenciais impactos sob o sistema multilateral de comércio.

Desse modo, o artigo se desenrola por meio da análise histórico-evolutiva das diferentes fases da relação entre o regionalismo e o sistema multilateral de comércio, com ênfase na perspectiva mais recente de percepção dos arranjos regionais como tentativa de expansão de modelos regulatórios, buscando preencher o espaço de regulamentação de temas deixados pela agenda multilateral.

Inicialmente é necessário explicitar que, embora o regionalismo fosse existente já à época do GATT 1947, a proliferação dos blocos regionais é fenômeno que se relaciona diretamente com as modificações da sociedade internacional nas últimas décadas do século XX. A nova conformação das forças políticas após a queda do Muro de Berlim trouxe mudanças que propiciaram a ascensão dos blocos regionais como alternativa à satisfação de interesses de atores no interior dos Estados, diante da globalização e de tentativas de contraposição a este fenômeno.

1 LAFER, Celso. Comércio, desarmamento e direitos bumanos: reflexões sobre uma experiência diplomática. São Paulo: Paz e Terra,
Aquela reconfiguração do cenário internacional significou uma alteração substancial nos paradigmas econômico, comercial, político e social, afetando intensamente a estrutura e o papel do Estado-nação, que, ao perder sua centralidade tradicional enquanto unidade privilegiada de condução ou controle dos fluxos de pessoas, bens, capitais ou ideias, se mostra então insuficiente para responder às novas necessidades da sociedade internacional. ${ }^{2,}$,

Observa-se, ainda, que o regionalismo tem abarcado, desde sua origem, diferentes modos deinstitucionalização, de acordo com os interesses dos Estados participantes na integração, e essa diversidade tem se manifestado de forma marcante na atualidade. ${ }^{4}$ A complexidade da temática consiste na dimensão política do processo de integração, que não pode ser dissociada dos aspectos jurídico e econômico, vez que a estratégia e o nível de aprofundamento dependem necessariamente da vontade política dos Estados que decidem se aproximar.

A partir da década de 1980, contudo, o fenômeno do regionalismo demonstrou não apenas novo fôlego, mas inovadora configuração. ${ }^{67} \mathrm{O}$ então "novo regionalismo" se diferencia substancialmente, por ultrapassar a pauta das questões tarifárias, incorporando novas temáticas ${ }^{8}$ e relacionando-se com a mudança na geografia do poder mundial em sentido mais amplo.

Por um lado, o novo regionalismo é identificado, de modo geral, com o regionalismo aberto, por sua interação com o mercado exterior e com a liberalização multilateral. ${ }^{9}$ Sob tal perspectiva, haveria uma tendência

1993. p. 33.

2 MENEZES, Wagner. Ordem global e transnormatividade. Ijui: Unijui, 2005.

3 SILVA, Roberto Luiz. Direito comunitário e da integração. Porto Alegre: Síntese, 1999. p. 23.

4 AMARAL JÚNIOR, Alberto do. A solução de controvérsias na OMC. São Paulo: Atlas, 2008. p. 29.

5 CELLI JUNIOR, Umberto. Teoria geral da integração: em busca de um modelo alternativo. In: MERCADANTE, Araminta de Azevedo; CELLI JUNIOR, Umberto; ARAÚJO, Leandro Rocha de (Orgs.). Blocos econômicos e integração na América Latina, África e Ásia. Curitiba: Juruá, 2003. p. 19.

6 HURRELL, Andrew. On global order: power, values and the constitution of international society. New York: Oxford University Press, 2007. p. 241.

7 FAWCETT, Louise. Regionalism in historical perspective. In: FAWCETT, Louise; HURRELL, Andrew. Regionalism in world politics. Oxford: Oxford University Press, 1995. p. 9.

8 HORN, Henrik; MAVROIDIS, Petros C.; SAPIR, André. Beyond the WTO?: an anatomy of EU and US preferential trade agreements. Brussels: Bruegel, 2009.

9 PRAZERES, Tatiana Lacerda. A OMC e os blocos regionais. São 
de conjugação dos Acordos Regionais de Comércio com a abertura econômica multilateral, ${ }^{10}$ como mecanismo mediante o qual os governos conduziriam sua inserção econômica mantendo relativa autonomia política. ${ }^{11}$ Por outro lado, contudo, a nova agenda do regionalismo bem como a sua arquitetura diferenciada - trouxe novas complexidades ao seu relacionamento com o sistema multilateral de comércio.

Assim, sob a nomenclatura de Acordos Regionais de Comércio (ARC), ou Acordos Preferenciais de Comércio (APC), ${ }^{12}$ identificaram-se, nessa onda de regionalismos, em face do sistema multilateral de comércio, quatro tendências principais: (i) o protagonismo desses Acordos nas políticas comerciais da maior parte dos Estados, superando a primazia do sistema multilateral; (ii) o crescente nível de sofisticação, nas áreas de normatividade e nos parceiros não necessariamente em contiguidade geográfica; (iii) o aumento dos acordos Norte-Sul, entre países desenvolvidos e em desenvolvimento; e (iv) a expansão e consolidação de um crescente número de ARC bilaterais entre blocos regionais de comércio de dimensão continental. ${ }^{1}$

Destaca-se, pois, que não é recente a preocupação de estudiosos com o futuro do sistema multilateral de comércio, face a essa proliferação dos Acordos Regionais. A percepção, entretanto, de que a formação de tais acordos tem se dado de forma livre e com regulamentação pouco efetiva, tem levado a doutrina a vislumbrar uma inversão nas relações econômicas internacionais, na qual o regionalismo perde seu caráter de exceção, constituindo uma regra, em potencial

Paulo: Aduaneiras, 2008. p. 150-151.

10 DEVLIN, Robert; ESTEVADEORDAL, Antoni. What's new in the new regionalism in the Americas? In: BULMERTHOMAS, Victor (Ed.). Regional integration in Latin America and the Caribbean: the political economy of open regionalism. London: Institute of Latin American Studies, University of London, 2001. p. 22.

11 CEPAL. Regionalismo abierto: un examen del concepto a la luz de las experiencias de América Latina y Asia y el Pacífico. In: _. Panorama de la inserción internacional de América Latina y el Caribe. LC/G.2085-P. Santiago: Naciones Unidas, 2001. p. 208.

12 Assim como os autores do estudo desenvolvido no âmbito da $\mathrm{OMC}$, as nomenclaturas são adotadas neste trabalho como termos intercambiáveis, embora existam outros autores que estabeleçam diferenças entre os ARC e os APC. Cf: FIORENTINO, Roberto; VERDEJA, Luis; TOQUEBOEUF, Christelle. The changing landscape of regional trade agreements: 2006 Update. WTO Discussion Paper n. 12. Geneva: WTO, 2007.

13 FIORENTINO, Roberto; VERDEJA, Luis; TOQUEBOEUF, Christelle. The changing landscape of regional trade agreements: 2006 Update. WTO Discussion Paper n. 12. Geneva: WTO, 2007. ameaça ao multilateralismo, exigindo mudanças dos Estados e/ou do sistema multilateral.

A fraca disciplina do tema, a dificuldade em se atingir um consenso e o interesse individual de parte dos Estados em deixar a questão livre de impedimentos nas relações internacionais contribuem para a erosão da não-discriminação no comércio internacional, ${ }^{15}$ bem como apontam para um risco de imposição assimétrica das regras do comércio internacional, como discutiremos adiante.

\section{Desenvolvimento}

\subsection{A dicotomia superada: stumbling blocs e building blocs}

Em uma visão global da literatura nesta temática, é possível reconhecer uma evolução, de modo correlato às ondas de acordos regionais de comércio, consubstanciada em três gerações distintas na doutrina. ${ }^{16}$

A primeira geração corresponde aos estudos originados a partir de Jacob Viner, que elabora os conceitos de criação de comércio (trade creation) e desvio de comércio (trade divertion), que compõem uma análise econômica dos efeitos dos acordos regionais face à liberalização multilateral. ${ }^{17} \mathrm{O}$ teste do desvio e criação de comércio formulado nessa primeira geração continua como ponto de partida relevante da análise dos efeitos econômicos da formação

14 O relatório acerca do futuro da OMC, elaborado com vistas a explorar os desafios institucionais da organização no novo milênio, denominado Sutherland Report em referência ao seu ccordenador, destaca a inversão ocorrida: "Yet nearly five decades after the founding of the GATT, MFN is no longer the rule; it is almost the exception. Certainly, much more trade between the major economies is still conducted on an MFN basis. However, what has been termed the "spaguetti bowl" of custom unions, common markets, regional and bilateral free trade areas, preferences and an endless assortment of miscellaneous trade deals has almost reached the poit where MFN treatment is exceptional treatment. Certainly the term might now be better defined as LFN, Least-Favored-Nation treatment. Does it matter? We belive it matters profoundly to the future of the WTO." CONSULTATIVE BOARD to the WTO Director-General. The Future of the WTO: Advancing Institutional Challenges in the New Milenium. (Sutherland Report). Geneva: WTO, 2004. p. 19.

15 MAVROIDIS, Petros. If you don't do someone else will (or won't): testing compliance of preferential trade agreements with the multilateral rules. Journal of World Trade. v. 40, n. 1, p. 187-214, 2006. p. 9.

16 THORSTENSEN, Vera. O multissistema da regulação do comércio global: proposta de novo referencial teórico e nova metodologia de análise. Revista Tempo do Mundo, Brasília, v. 3, n. 1. p. 89-115, 2011.

17 VINER, Jacob. The customs union issue. Washington DC: Anderson Kramer Associates, 1961. p. 44. 
de blocos, embora as críticas e refinamentos tenham levado a uma análise dos efeitos em uma perspectiva mais ampla pelos estudos que se seguiram.

A segunda geração de estudos nesta temática polarizou a discussão entre a identificação desses acordos como blocos de contenção $3 / 4$ stumbling blocs $3 / 4 \mathrm{da}$ liberalização do comércio multilateral, em uma relação de antagonismo, a percepção dos acordos regionais de comércio como building blocs, em complementariedade ao sistema multilateral. Essa dicotomia, embora tenha partido da geração anterior dos estudos econômicos, incorporou à discussão outros fatores não diretamente econômicos.

Sob o ponto de vista da tensão entre os Acordos Regionais e a OMC, criticam-se os efeitos do que Jagdish Bhagwati denominou spaguetti bowl, ${ }^{19}$ em referência ao emaranhado de regulamentações comerciais sobrepostas e inconsistentes entre si, que ameaçaria a transparência e a previsibilidade no comércio internacional, e resultaria no aumento dos custos de transação através dessa complexa arquitetura.

Ademais, afirma-se que os ARC podem desviar a atenção das negociações multilaterais, por motivos de recursos financeiros e humanos limitados destinados a negociações comerciais, e por razão da mudança de foco e perda de interesse político no sistema multilateral. ${ }^{20}$ A primeira hipótese é claramente o caso de países menos desenvolvidos, que não detêm corpo diplomático e recursos materiais suficientes para a participação simultânea em negociações regionais e multilaterais. A segunda hipótese se confunde com a observada perda de interesse de certos países no avanço das negociações multilaterais, resultado também dos entraves não solucionados da Rodada de Doha.

Por fim, alega-se que o tratamento de temas 'sensíveis' pelos sistemas regionais poderia prejudicar o consenso nas regras do comércio unilateral, por antecipar a percepção das dificuldades geradas por meio da adoção regional de regras em temas não diretamente comerciais (non trade issues).

18 MANSFIELD, Edward D.; MILNER, Helen V. The political economy of regionalism. New York: Columbia University Press, 1997. p. 22.

19 BHAGWATI, Jagdish. Preferential trade agreements: the wrong road. Law and Policy in International Business, v. 27, p. 865-890, 1996.

20 FIORENTINO, Roberto; VERDEJA, Luis; TOQUEBOEUF, Christelle. The changing landscape of regional trade agreements: 2006 Update. WTO Discussion Paper n. 12. Geneva: WTO, 2007. p. 11.
Por outro lado, sob a perspectiva da compatibilidade entre os acordos regionais e o sistema multilateral, afirma-se que os Acordos Regionais, devido ao número reduzido de participantes, conseguiriam alcançar liberalizações mais profundas que o sistema de negociações multilaterais. Assim, ao promoverem a liberalização regional, tem-se que os Acordos Regionais favorecem o caminho ao livre comércio, objetivo basilar do sistema multilateral.

Ademais, os arranjos regionais com frequência aprofundam os compromissos já acordados, ou incluem compromissos em áreas ainda não abrangidas pelas obrigações da OMC. O estabelecimento de compromissos mais profundos $3 / 4$ WTO-plus $3 / 4,{ }^{21}$ e de compromissos que ultrapassam as áreas atualmente disciplinadas $3 / 4$ WTO-extra $3 / 4,22$ ao mesmo tempo em que são apresentados por alguns como prejudiciais ao consenso na OMC, pois escancaram as dificuldades de implementação e malefícios por parte dos países em desenvolvimento, são também interpretados como antecedentes positivos às negociações multilaterais. ${ }^{23}$

A perspectiva nesse ponto parte da ideia de que os compromissos regionais representam consensos parciais entre os membros da OMC, oferecendo precedente útil às negociações multilaterais, também por meio da formação de alianças e fortalecimento das relações entre parceiros comerciais. Embora haja a possibilidade, em temas como direitos trabalhistas e meio ambiente, de regulamentações divergentes $e$ discriminatórias a partir da multiplicidade de arranjos regionais, as demandas do mercado e os custos da aplicação de diversas regulamentações diferentes empurrariam os membros para a convergência, através da harmonização e unificação das regras. ${ }^{24}$

Além do precedente ao consenso, o tratamento pelos Acordos Regionais de temas além das obrigações

21 A expressão WTO-plus é utilizada na doutrina em referência a Acordos que tratam de temas previstos na OMC, mas estabelecem compromissos mais onerosos que a disciplina do sistema multilateral.

22 A expressão WTO-extra é utilizada na doutrina em referência a Acordos que tratam de temas ainda não disciplinados pelo sistema multilateral.

23 CEPAL. Regionalismo abierto: un examen del concepto a la luz de las experiencias de América Latina y Asia y el Pacífico. In: _. Panorama de la inserción internacional de América Latina y el Caribe. LC/G.2085-P. Santiago: Naciones Unidas, 2001. p. 210.

24 FIORENTINO, Roberto; VERDEJA, Luis; TOQUEBOEUF, Christelle. The changing landscape of regional trade agreements: 2006 Update. WTO Discussion Paper n. 12. Geneva: WTO, 2007. p. 8. 
da OMC poderia oferecer experiências concretas de implementação que conseguem auxiliar o sistema multilateral a regulamentar esses temas de maneira menos "traumática" aos Estados. Nesse aspecto, os Acordos Regionais funcionariam como uma experiência preliminar, na qual a negociação e implementação de regras em temas "sensíveis" poderia ensinar aos negociadores multilaterais, expondo o melhor caminho para a inclusão desses novos temas na agenda da OMC.

Contudo, em superação desta dicotomia, a geração atual de estudos se concentra no aspecto concreto e real da temática, propondo análises específicas dos principais Acordos Regionais existentes, exames de compatibilidade de regras determinadas com a normativa multilateral e mecanismos concretos de multilateralização das regras regionais. ${ }^{25}$

A superação da dicotomia clássica por essa nova geração de estudos é resultado, pois, de mudanças concretas na arquitetura das relações econômicas internacionais observadas nos últimos anos. ${ }^{26}$ Não se pode ignorar, ainda, que a recente crise econômica mundial e o fracasso nas negociações de novos compromissos na OMC conferiram combustível adicional à conclusão de Acordos Regionais pelos principais atores das relações internacionais. Esse quadro acaba por extremar as previsões, levando à percepção de objetivos implícitos de exportação de um modelo regulatório na conclusão de pacotes de Acordos Regionais, como veremos adiante.

\subsection{O regionalismo do século XXI como vetor para imposição de modelos normativos}

$\mathrm{Na}$ atualidade, verifica-se a necessidade de uma revisão substancial e global do tratamento do regionalismo em relação ao sistema multilateral, de modo a preencher o espaço existente entre o regionalismo do Século XXI e as regras do Século XX. ${ }^{27}$ Por suas características únicas, o regionalismo deste século exige uma rearquitetura de regras e estratégias existentes.

25 BALDWIN, Richard. Multilateralizing regionalism: spaguetti bowls as building blocks on the path to global free trade. The World Economy, v. 29, n. 11, p. 1451-1518, 2006.

26 BALDWIN, Richard. 21th century regionalism: filling the gap between 21th century trade and 20th century rules. Geneva: World Trade Organization, Economic Research and Statistics Division, 2011.

27 BALDWIN, Richard. 21th century regionalism: filling the gap between 21 th century trade and 20th century rules. Geneva: World Trade Organization, Economic Research and Statistics Division, 2011.
Como bem destaca Richard Baldwin, a revolução tecnológica-informacional-comunicacional promoveu uma real internacionalização das cadeias produtivas, que trouxe a imbricação entre (i) o comércio; (ii) os investimentos e (iii) os serviços ao centro do comércio internacional. Essa nova configuração exige normas complexas para sua regulação, que abarquem tais temáticas. ${ }^{28}$

O autor complementa sua teoria da multilateralização do regionalismo, com um estudo no qual, após evidenciar novas complexidades da relação entre o multilateralismo e o regionalismo, clama por um novo quadro regulatório do comércio internacional. $\mathrm{O}$ nexo entre (i) comércio, (ii) investimentos e (iii) serviços passou a ser elemento central e característica distintiva do comércio internacional no Século XXI. ${ }^{2}$

Como consequência, as principais barreiras ao comércio neste século não são as tarifárias, mas aquelas relacionadas à defesa da concorrência, ao trânsito de capitais, aos direitos de propriedade intelectual e à segurança de investimentos. Estes são, pois, temas que já foram implementados no interior dos Estados desenvolvidos, mas ainda necessitam de regulamentação doméstica nos demais Estados. Deste modo, o regionalismo atual passaria a preencher, através de Acordos Regionais “profundos”, o espaço de regulamentação desses temas, juntamente com reformas unilaterais e Tratados Bilaterais de Investimentos. ${ }^{30}$

Desse modo, o regionalismo do século XXI é direcionado por forças políticas e econômicas interessadas em reformas regulatórias internas, diferentemente das forças interessadas no acesso a mercados que dirigiam o regionalismo do século XX. A regulação segundo certos interesses passa a ser o objetivo buscado e, neste ponto, o regionalismo poderia ameaçar o papel da OMC como locus de formulação multilateral de regras do comércio internacional.

28 BALDWIN, Richard. 21th century regionalism: filling the gap between 21 th century trade and 20th century rules. Geneva: World Trade Organization, Economic Research and Statistics Division, 2011. p. 5.

29 BALDWIN, Richard. 21th century regionalism: filling the gap between 21 th century trade and 20th century rules. Geneva: World Trade Organization, Economic Research and Statistics Division, 2011. p. 10.

30 BALDWIN, Richard. 21th century regionalism: filling the gap between 21 th century trade and 20th century rules. Geneva: World Trade Organization, Economic Research and Statistics Division, 2011. p. $10-25$. 
Nessa perspectiva, toda a sistemática de negociação $3 / 4$ regional ou multilateral $3 / 4$ passa a circular não mais em função de barganhas para o acesso a mercados através de cortes tarifários, mas em torno da capacidade de expansão do modelo regulatório ao qual um polo já esteja vinculado. A função dos grupos de interesse interno assume força determinante da política comercial, ao exercer influência substancial sob as negociações nas diferentes esferas $3 / 4$ multilateral, regional e unilateral. ${ }^{3}$

É assim também que Vera Thorstensen propõe uma visão integrada da regulação do comércio global, que passaria por uma análise transversal das dimensões normativas relacionadas ao comércio internacional, visando a uma melhor compreensão dos efeitos cruzados entre o sistema multilateral-plurilateral, os sistemas preferenciais, e os sistemas nacionais de comércio externo. ${ }^{32}$

A autora também destaca a relevância central de uma análise atenta do mapeamento dos acordos preferenciais negociados por um certo parceiro, uma vez que a concentração de países com acordos em torno de um eixo evidencia padrões de regras que depois serão levadas às instâncias multilaterais. E, assim, se um número significativo de países adotar certo modelo regulatório, o grau de liberdade possível para a negociação multilateral ou a posterior inclusão de outros países no grupo será limitada. ${ }^{33}$ Assim, a formação de acordos regionais de

31 BALDWIN, Richard. 21th Century Regionalism: Filling the gap between 21th century trade and 20th century rules. Geneva: World Trade Organization, Economic Research and Statistics Division, 2011. p. 23-25.

32 Assim a autora explicita: "Uma visão integrada da regulação do comércio global, sob essa ótica, passa a abranger não apenas a análise em sequência dos diferentes sistemas de regulação que

definem o comércio internacional - incluindo temas diretamente ligados ao comércio, temas relacionados ao comércio e temas

que afetam o comércio -, mas também, e sobretudo, uma maior compreensão dos efeitos cruzados entre os diversos sistemas: i) o sistema multilateral-plurilateral, criado por meio de negociações internacionais entre membros de organizações internacionais e/ ou tratados internacionais negociados por uma parcela significativa de países; ii) os sistemas preferenciais (regionais, bilaterais, não recíprocos), negociados pelas partes de acordos comerciais de diferentes níveis de integração econômica; e iii) os sistemas nacionais de comércio externo, negociados internamente pelos principais parceiros internacionais, e definidos por suas políticas de comércio externo." THORSTENSEN, Vera. O multissistema da regulação do comércio global: proposta de novo referencial teórico e nova metodologia de análise. Revista Tempo do Mundo, Brasília, v. 3, n. 1. p. 89-115, 2011. p. 93-94.

33 THORSTENSEN, Vera. O multissistema da regulação do comércio global: proposta de novo referencial teórico e nova metodologia de análise. Revista Tempo do Mundo, Brasília, v. 3, n. 1. p. 89-115, 2011. p. 98. comércio com compromissos regulatórios para além da disciplina multilateral pode influenciar na capacidade de um Estado em tornar-se um agente de construção da governança do comércio internacional. ${ }^{34}$

É nesse sentido que o regionalismo assume novo papel nas relações internacionais, polarizando modelos normativos que paulatinamente tendem a se cristalizar, trazendo uma pressão à sua adoção pelos demais países, e privilegiando interesses dos Estados centrais que iniciaram o respectivo polo. Este contexto exige, portanto, uma postura crítica e proativa dos Estados em desenvolvimento $3 / 4$ e dos países latino-americanos $3 / 4 \mathrm{sob}$ o risco de diluírem-se na corrente normativa, e acabarem importando modelos regulatórios que lhes desfavoreçam.

\subsection{Os modelos normativos europeus e norte- americanos}

Partindo desse novo contexto, Henrik Horn, Petros Mavroidis e André Sapir desenvolveram pesquisa empírica com o objetivo de mapear os Acordos Regionais de Comércio sob a perspectiva da 'profundidade' de seus compromissos em face dos Acordos da OMC. Tendo em vista que o emaranhado de Acordos Regionais seguindo um padrão próprio é estratégia adotada há décadas pela União Europeia ${ }^{35}$ e Estados Unidos $3 / 4$ seguida bem mais recentemente pelo Japão $3 / 4{ }^{36}$, a pesquisa focou sua análise sob os dois primeiros agentes.

34 THORSTENSEN, Vera; et al. A multiplicação dos acordos preferenciais de comércio e o isolamento do Brasil. 2013. Disponível em: $<$ http://retaguarda.iedi.org.br/midias/artigos/51d18e9168afa9d0. pdf $>$. Acesso em: 30 nov. 2014.

35 Na pesquisa em questão utiliza-se do termo "Comunidade Europeia" para se referir à atuação da União Europeia na sociedade internacional. Não se pretende adentrar na eventual distinção conceitual entre ambas as expressões, limitando-se à destacar que esta discussão perde sentido desde a ratificação do Tratado de Lisboa, que prevê textualmente que a União Europeia substituiu e sucedeu à Comunidade Europeia. Neste sentido, a nomenclatura adotada nos documentos oficiais da OMC passou a ser "União Europeia".

36 Pesquisas recentes apontam também o papel da China, que buscaria crescentemente também construir um modelo próprio para seus arranjos regionais, seguindo a tendência dos outros global players. Cf: SANCHEZ BADIN, Michelle Ratton. Compromissos assumidos por grandes e médias economias em Acordos Preferenciais de Comércio: o contraponto entre União Europeia e Estados Unidos e China e Índia. Brasília: IPEA, 2012. p. 14.

37 HORN, Henrik; MAVROIDIS, Petros C.; SAPIR, André. Beyond the WTO?: an anatomy of EU and US preferential trade agreements. Brussels: Bruegel, 2009. 
Após análise detida dos Acordos Regionais então registrados perante o Secretariado da OMC que tinham como parte respectivamente a União Europeia e os Estados Unidos, os autores concluíram que estes escolheram estratégias notadamente distintas em relação à tipificação das cláusulas além da normatividade consolidada no âmbito multilateral.

Primeiramente, foi detectada uma "inflação normativa" nos Acordos direcionados pela União Europeia, que continham o quádruplo do número de dispositivos WTO-extra, mas muitos deles continham obrigações não exigíveis juridicamente. Dentre os temas inovadores, os acordos direcionados pela UE continham disposições relativas às políticas de concorrência e os acordos dos EUA continham dispositivos relacionados a padrões trabalhistas e ambientais.

Embora entendam que o estudo não permitiria apontar diferenças precisas nestas estratégias, os autores explicitam a percepção de que estes dispositivos que expressam uma 'inflação normativa' são disposições relacionadas à temática do desenvolvimento, o que sugeriria uma necessidade da UE em posicionar seus Acordos regionais como não puramente ligados a interesses comerciais. Este aspecto pode se relacionar, ainda, a uma falta de consenso entre os estados-membros da UE sobre os objetivos principais desses acordos.

A segunda conclusão principal do estudo explicita que os dispositivos de fato exigíveis juridicamente são poucos tanto nos Acordos centralizados na UE quanto nos Acordos centralizados nos EUA, e se referem majoritariamente a áreas já existentes nos Acordos da $\mathrm{OMC}$, tais como investimentos, trânsito de capitais e propriedade intelectual (WTO-plus).

A conclusão final do estudo se refere à constatação de que as disposições existentes em áreas inovadoras têm um caráter claramente regulatório, o que sugere que os acordos capitaneados pela UE e EUA se prestam a atuar como meios para que os dois polos exportem e expandam seus respectivos modelos regulatórios a seus parceiros de acordos regionais. E, assim, chamam a atenção ao potencial dano à justiça das relações comerciais internacionais:

Este estudo não nos permite tirar conclusões sobre os custos e os benefícios desta situação para os "hubs and spokes", mas a nossa impressão é que ele atende principalmente os interesses dos dois "reguladores do mundo". Esta impressão é baseada no fato de que as disposições OMC-extra juridicamente vinculantes incluídas nos acordos da CE e dos EUA foram todos objeto de tentativas anteriores, mas mal sucedidas, por parte da UE e / ou dos EUA para incorporá-las em regras da OMC, contra os desejos dos países em desenvolvimento. Na medida em que nossa conclusão é correta, ela apoia a visão acima mencionada que APC são fontes de preocupação com a injustiça nas relações comerciais ${ }^{38}$

O Secretariado da OMC aplicou metodologia similar em pesquisa com um universo mais amplo de acordos regionais, destacando o novo foco dos ARC em formação. ${ }^{39}$ Este segundo estudo reforça a tendência de aprofundamento dos novos acordos regionais de comércio em matérias além das disciplinadas multilateralmente, o que aponta o caráter regulatório dos compromissos assumidos e sua crescente relevância para a disciplina do comércio global. ${ }^{40}$

38 Tradução livre do original em língua inglesa: "This study does not permit us to draw conclusions about the costs and benefits of this situation for the hubs and the spokes, but our impression is that it primarily serves the interests of the two 'regulators of the world'. This impression is based on the fact that the legally enforceable WTO-X provisions included in EC and US agreements have all been the subject of earlier, but failed, attempts by the EU and/or the US to incorporate them into WTO rules, against the wishes of developing countries. To the extent that our conclusion is correct, it supports the above-mentioned view that PTAs are breeding concern about unfairness in trade relations." HORN, Henrik; MAVROIDIS, Petros C.; SAPIR, André. Beyond the WTO?: an anatomy of EU and US preferential trade agreements. Brussels: Bruegel, 2009. p. 7.

39 Assim, o estudo indica: "As preferential agreements have evolved over time, however, the lowering of tariffs is no longer the main focus of PTAs. Agreements now cover a wider number of issues - beyond tariffs - and involve more structured institutional arrangements. Traditional theories about PTAs fail to explain these new developments, both in terms of the causes and consequences of "deep" agreements. In particular, traditional theories are silent on the relationship between the growth of international production networks and the formation of deeper policy arrangements among countries. While the above discussion has shed some light on the causes and the structure of deep integration agreements - a discussion that falls mostly outside the domain of trade economics

- there is clearly a need for further research in this area. WORLD TRADE ORGANIZATION. World Trade Report 2011. The WTO and preferential trade agreements: from co-existence to coherence. Geneva: WTO, 2011. p. 114.

40 O estudo confirma a hipótese dos autores Horn, Mavroidis e Sapir: "The pattern between developed and developing countries observed in the portion of Figure D.9 dealing with WTO-X provisions is consistent with the argument made by HMS that developed countries are seeking to "export" their regulatory regimes to developing countries. WORLD TRADE ORGANIZATION. World Trade Report 2011. The WTO and preferential trade agreements: from co-existence to coherence. Geneva: WTO, 2011. p. 132. 


\subsection{Em busca de um modelo latino-americano}

Enquanto os EUA e a União Europeia desenvolvem seus respectivos modelos normativos, e promovem a sua crescente expansão em um contexto de diminuição de esforços no âmbito multilateral, os países da América Latina adotam perspectivas difusas sobre a temática. ${ }^{41}$

Alguns países, como México e Chile, têm buscado o estabelecimento de Acordos Regionais de Comércio com padrões regulatórios similares ao NAFTA, o que lhes situa mais fortemente na zona de influência do modelo regulador norte-americano. Os aparentes frutos econômicos surgidos a esses países estimularam outros a seguirem esta estratégia de celebração de ARC mais recentemente, tais como Colômbia, Peru e Equador. No caso do Chile, que há algumas décadas adota a formação de Acordos Bilaterais como estratégia de inserção internacional, houve inclusive a substituição de acordos anteriormente formados com parceiros da América Latina por outros no modelo no NAFTA, o que poderia sugerir uma concreta replicação do modelo norte-americano como expressão da primazia desses interesses. ${ }^{42}$

De modo geral, os demais países da América Latina seguem apostando em esquemas regionais anteriormente constituídos 3/4 ALADI e MERCOSUL $3 / 4$, não se atentando para o valor de outros ARC em termos de participação na construção do modelo regulatório internacional. Ademais, é preciso destacar que, devido ao nível de consolidação jurídica-

41 Embora não seja objeto deste estudo, cumpre destacar que o conceito de América Latina é relativo, e a expressão, como categoria classificadora de povos com diversas culturas, merece reflexão. De modo geral, o conceito se relaciona ao compartilhamento do sentido da exploração colonial, embora com inegáveis variáveis próprias da colonização portuguesa e hispânica, que seria, portanto, uma característica comum às atuais ex-colônias tropicais na América, nas quais diversos autores visualizam uma identidade contemporânea de subdesenvolvimento.

42 Os autores fazem este diagnóstico: "A maioria desses acordos são TLCs de natureza semelhante à do NAFTA, sendo que este formato de acordo tem substituído anteriores ACEs que o Chile havia feito com alguns países latino-americanos na década de 1990, como no caso de Peru e Colômbia. Isso porque, segundo Sáez e Valdés (1999), o governo chileno tem estimulado a inclusão das distintas dimensões do comércio, reflexo da maior complexidade das relações econômicas, o que não está presente nos ACEs. Além disso, Kuwayama e Kuwayama (2002) sugerem que o fato de o Chile fazer TLC no modelo NAFTA seria uma forma de reduzir os problemas de coordenação que podem surgir com o grande número de acordos bilaterais." p. 670 CARVALHO, Carlos Eduardo; LOPES, Renata Rossetto. Acordos bilaterais de comércio como estratégia de inserção regional e internacional do Chile. Contexto Internacional, v. 32, n. 2, p. 643-693, jul/dez. 2010. institucional alcançado por estes esquemas, há obstáculo formal à celebração de novos ARC pelos países em separado, exigindo-se uma negociação em bloco com os demais parceiros, o que por si só pode dificultar a formação desses novos ARC e a construção de um modelo normativo latino-americano.

No tocante ao Brasil, é possível identificar um verdadeiro "isolamento" do país no contexto da formação desses novos ARC, e potencialmente na construção do modelo regulatório global, uma vez que o país sempre privilegiou a esfera multilateral para negociações comerciais, o que tem resultado na inexistência de construção um modelo de acordo embasado nos interesses brasileiros. ${ }^{43}$

Em estudo que traça claramente este diagnóstico, Vera Thorstensen et al identificam no diminuto número de ARC celebrados pelo país, os vetores regional e extrarregional. $\mathrm{O}$ vetor regional encontra-se polarizado pelo MERCOSUL, que por sua vez insere-se no âmbito da ALADI. ${ }^{44}$ No vetor extrarregional, os acordos existentes foram celebrados pelo país em conjunto com os demais parceiros do MERCOSUL, e o maior destaque é conferido ao acordo em negociação com a UE. ${ }^{45}$ Em ambos os vetores, contudo, as regras contidas nestes APC inovam pouco em relação à normatividade multilateral, apresentando principalmente uma retomada de regras dos acordos da OMC. ${ }^{46}$

43 THORSTENSEN, Vera; et al. A multiplicação dos acordos preferenciais de comércio e o isolamento do Brasil. 2013. Disponível em: $<$ http://retaguarda.iedi.org.br/midias/artigos/51d18e9168afa9d0. pdf>. Acesso em: 30 nov. 2014.

44 Assim enumeram os autores: "Nesse contexto, foram celebrados acordos entre os membros do Mercosul e: (i) Chile; (ii) Bolívia; (iii) México (geral); (iv) México (setor automotivo); (v) Peru; (vi) Colômbia, Equador e Venezuela; e (vii) Cuba. O Brasil também assinou acordos com: (i) Guiana e (ii) Suriname (apenas arroz)." THORSTENSEN, Vera; et al. A multiplicação dos acordos preferenciais de comércio e o isolamento do Brasil. 2013. Disponível em: $<$ http://retaguarda.iedi.org.br/midias/artigos/51d18e9168afa9d0. pdf $>$. Acesso em: 30 nov. 2014.

45 Assim explicitam os autores: "No âmbito extraregional, o Brasil, em conjunto com o Mercosul, é signatário de APCs com: (i) Índia, (ii) Israel; (iii) União Aduaneira do Sul da África - SACU ; (iv) Egito; e (v) Palestina, dos quais apenas dois primeiros estão em vigor. Destaca-se, também, a atual negociação de um APC entre Mercosul e União Européia." THORSTENSEN, Vera; et al. A multiplicação dos acordos preferenciais de comércio e o isolamento do Brasil. 2013. Disponível em: <http://retaguarda.iedi.org.br/midias/ artigos/51d18e9168afa9d0.pdf>. Acesso em: 30 nov. 2014.

46 A este respeito, confira-se: "Finalmente, em novos temas, pouca regulamentação é de fato encontrada nos acordos constitutivos e também naqueles assinados entre Brasil ou Mercosul e outros parceiros. Em grande parte, a regulamentação se restringe a acordos mais específicos dentro de cada área, que são regulados eminentemente no Mercosul, com exceção da temática de meio ambiente, também 
A estagnação na celebração de novos acordos pelo país pode levar não somente à perda relativa de preferências tarifárias pelo Brasil em relação a outros países da América Latina que continuem negociando com outros parceiros, mas principalmente pode abrir espaço para o fortalecimento do modelo norteamericano no continente. Isso pois a Aliança do Pacífico $3 / 4$ formada entre Chile, Colômbia, Peru e México $3 / 4-$ tem a potencialidade de constituir-se como um centro replicador do modelo de integração postulado pelos ARC com padrão regulatório norte-americano e em defesa de seus respectivos interesses. ${ }^{47}$

Diante deste quadro, Vera Thorstensen et al concluem:

Com a necessidade de atualização das regras da OMC e do impasse nas negociações da Rodada Doha, a regulação do comércio se dará, sobretudo, no âmbito dos APCs. Desse modo, o Brasil deverá intensificar o processo de integração tanto no vetor regional quanto no extraregional, além de definir as regras que julgue necessárias negociar para esse novo cenário comercial, tais como regras de origem, medidas não tarifárias, serviços e investimentos, dentre outros. Apenas assim o Brasil poderá garantir sua posição como um rule maker e não um rule taker na governança do comércio internacional. ${ }^{48}$

Assim, compartilha-se a compreensão explicitada pelo estudo supracitado de que o Brasil deve assumir um papel proativo na construção de novos acordos, que busquem construir um modelo regulatório que esteja mais diretamente ligado aos interesses nacionais, e que possam contribuir para um modelo regulatório latino-americano.

regulada pela Aladi. O Mercosul possui regulamentação nas áreas de concorrência, compras governamentais, meio ambiente e cláusula social, sendo que apenas estas duas últimas estão em vigor." p. 65. SANCHEZ BADIN, Michelle Ratton; CARVALHO, Marina Amaral Egydio de; RORIZ, João Henrique Ribeiro. Os acordos regionais e preferenciais de comércio do Brasil com o seu entorno. In: BAUMANN, Renato; OLIVEIRA, Ivan Tiago Machado (Orgs.). Os BRICS e seus vizinhos: comércio e acordos regionais. Brasília: Ipea, 2014. p. 55-101.

47 MENEZES, Roberto Goulart. A Aliança do Pacífico e a estratégia de integração Sul-Americana do Brasil. IX Encontro da ABCP. Política Internacional. Brasília, ago. 2014. Disponível em: <http://www.encontroabcp2014.cienciapolitica.org.br/ resources/anais/14/1403747928_ARQUIVO_Aestrategia deintegracaoregionalbrasileiraeaAliancadoPacificoABCP2014. pdf $>$ Acesso em: 30 nov. 2014.

48 HORSTENSEN, Vera; et al. A multiplicação dos acordos preferenciais de comércio e o isolamento do Brasil. 2013. Disponível em: <http:// retaguarda.iedi.org.br/midias/artigos/51d18e9168afa9d0.pdf > . Acesso em: 30 nov. 2014.

\section{Comentários finais: desafios e perspectivas}

Conforme se verificou, se por um lado a UE e os EUA têm construído suas redes regulatórias, utilizando-se de sua influência para garantir parceiros em seus Acordos Regionais, e pressionado para que os padrões que lhes interessam sejam impostos, os países da América Latina não possuem posicionamento sólido neste aspecto relevante das relações comerciais internacionais na contemporaneidade. Assim, embora alguns países tenham escolhido vincular-se ao polo norte-americano, os demais países da América Latina permanecem vinculados aos respectivos esquemas regionais consolidados, conferindo atenção secundária à formação de novos acordos regionais, o que seria uma possibilidade de participar desta paulatina construção da normatividade internacional.

Contudo, essa nova configuração da rede de Acordos Regionais impõe novos desafios à participação dos países latino-americanos no cenário internacional, e exige novos paradigmas de tratamento da temática do regionalismo por esses Estados. Desse modo, diante do diagnóstico da polarização entre os Acordos Regionais sob os eixos norte-americano e europeu, a partir de seus respectivos moldes e interesses, ${ }^{49}$ há um chamamento à participação mais efetiva e consciente dos países emergentes $3 / 4 \mathrm{e}$ especialmente do Brasil $3 / 4$ na construção dessa arquitetura institucional regulatória, pois a normatividade que hoje parece diluída tende a se cristalizar, exatamente devido à tipologia dos compromissos abarcados, que importam implicações jurídico-institucionais domésticas duradouras.

O novo desafio que o regionalismo coloca, portanto, ao sistema multilateral é sutil, ao ameaçar a legitimidade do sistema em sua capacidade de congregar distintos interesses e construir entendimentos. Nesse sentido, não se trata apenas de promover a multilateralização do regionalismo, mas de que maneira isto será concretizado. A multilateralização de um modelo hegemônico, que favoreça apenas os Estados desenvolvidos, parece se distanciar dos objetivos globais que vislumbramos no sistema multilateral de comércio. Esses objetivos não se limitam à promoção do livre comércio, mas incluem a manutenção da paz, a promoção do desenvolvimento econômico e do bem-estar mundial, o alcance do desenvolvimento sustentável e a proteção ambiental, a redução da pobreza e a gerência de crises econômicas globais. ${ }^{50}$

49 HORN, Henrik; MAVROIDIS, Petros C.; SAPIR, André. Beyond the WTO?: an anatomy of EU and US preferential trade agreements. Brussels: Bruegel, 2009. p. 7.

50 JACKSON, John. H. Sovereignty, the WTO, and changing fundamentals of international law. Cambridge: Cambridge University Press, 2006. p. 86. 


\section{Referências}

AMARALJÚNIOR, Alberto do. A solução de controvérsias na OMC. São Paulo: Atlas, 2008.

BALDWIN, Richard. 21th century regionalism: filling the gap between 21th century trade and 20th century rules. Geneva: World Trade Organization, Economic Research and Statistics Division, 2011.

BALDWIN, Richard. Multilateralizing regionalism: spaguetti bowls as building blocs on the path to global free trade. The World Economy, v. 29, n. 11, p. 1451-1518, 2006.

BHAGWATI, Jagdish. Preferential Trade Agreements: the wrong road. Law and policy in international business, v. 27, 1996, p. 865-90, 1996.

CARVALHO, Carlos Eduardo; LOPES, Renata Rossetto. Acordos bilaterais de comércio como etratégia de inserção regional e internacional do Chile. Contexto Internacional, v. 32, n. 2, p. 643-693, jul/dez. 2010.

CELLI JUNIOR, Umberto. Teoria geral da integração: em busca de um modelo alternativo. In: MERCADANTE, Araminta de Azevedo; CELLI JUNIOR, Umberto; ARAÚJO, Leandro Rocha de (Orgs.). Blocos econômicos e integração na América Latina, Africa e Ásia. Curitiba: Juruá, 2003.

CEPAL. Regionalismo abierto: un examen del concepto a la luz de las experiencias de América Latina y Asia y el Pacífico. In: - Panorama de la inserción internacional de América Latina y el Caribe. LC/G.2085-P. Santiago: Naciones Unidas, 2001.

CONSULTATIVE BOARD to the WTO DirectorGeneral. The future of the WTO: advancing institutional challenges in the new milenium. (Sutherland Report). Geneva: WTO, 2004.

DEVLIN, Robert; ESTEVADEORDAL, Antoni. What's new in the new regionalism in the Americas? In: BULMER-THOMAS, Victor (Ed.). Regional integration in Latin America and the Caribbean: the political economy of open regionalism. London: Institute of Latin American Studies, University of London, 2001.

FAWCETT, Louise. Regionalism in historical perspective. In: FAWCETT, Louise; HURRELL,
Andrew. Regionalism in world politics. Oxford: Oxford University Press, 1995.

FIORENTINO, Roberto; VERDEJA, Luis; TOQUEBOEUF, Christelle. The changing landscape of regional trade agreements: 2006 update. Geneva: WTO, 2007.

HORN, Henrik; MAVROIDIS, Petros C.; SAPIR, André. Beyond the WTO?: an anatomy of EU and US preferential trade agreements. Brussels: Bruegel, 2009.

HURRELL, Andrew. On global order: power, values and the constitution of international society. New York: Oxford University Press, 2007.

JACKSON, John. H. Sovereignty, the WTO, and changing fundamentals of international law. Cambridge: Cambridge University Press, 2006.

LAFER, Celso. Comércio, desarmamento e direitos humanos: reflexões sobre uma experiência diplomática. São Paulo: Paz e Terra, 1993.

MANSFIELD, Edward D.; MILNER, Helen V. The political economy of regionalism. New York: Columbia University Press, 1997.

MAVROIDIS, Petros. If you don't do someone else will (or won't): testing compliance of preferential trade agreements with the multilateral rules. Journal of World Trade, v. 40, n. 1, p. 187-214, 2006.

MENEZES, Roberto Goulart. A Aliança do Pacifico e a estratégia de integração Sul-Americana do Brasil. IX Encontro da ABCP. Política Internacional. Brasília, 2014. Disponível em: <http://www.encontroabcp2014. cienciapolitica.org.br/resources/anais/14/1403747928_ ARQUIVO_Aestrategiadeintegracaoregionalbrasileir aeaAliancadoPacificoABCP2014.pdf> Acesso em: 30 nov. 2014.

MENEZES, Wagner. Ordem global e transnormatividade. Ijui: Unijui, 2005.

PRAZERES, Tatiana Lacerda. A OMC e os blocos regionais. São Paulo: Aduaneiras, 2008.

SANCHEZ BADIN, Michelle Ratton. Compromissos assumidospor grandes e médias economias em acordospreferenciais 
de comércio: o contraponto entre União Europeia e Estados Unidos e China e Índia. Brasília: Ipea, 2012.

SANCHEZ BADIN, Michelle Ratton; CARVALHO, Marina Amaral Egydio de; RORIZ, João Henrique Ribeiro. Os acordos regionais e preferenciais de comércio do Brasil com o seu entorno. In: BAUMANN, Renato; OLIVEIRA, Ivan Tiago Machado (Orgs.). Os BRICS e seus vizzinhos : comércio e acordos regionais. Brasília: Ipea, 2014.

SILVA, Roberto Luiz. Direito comunitário e da integração. Porto Alegre: Síntese, 1999.

THORSTENSEN, Vera. O Multissistema da Regulação do Comércio Global: proposta de novo referencial teórico e nova metodologia de análise. Revista Tempo do Mundo, Brasília, v. 3, n. 1. p. 89-115, 2011.

THORSTENSEN, Vera et al. A multiplicaşão dos acordos preferenciais de comércio e o isolamento do Brasil. 2013. Disponível em: <http://retaguarda.iedi.org.br/midias/ artigos/51d18e9168afa9d0.pdf>. Acesso em: 30 nov. 2014.

VINER, Jacob. The customs union issue. Washington DC: Anderson Kramer Associates, 1961.

WORLD TRADE ORGANIZATION. World Trade Report 2011. The WTO and preferential trade agreements: from co-existence to coherence. Geneva: WTO, 2011. 
Para publicar na Revista de Direito Internacional, acesse o endereço eletrônico www.rdi.uniceub.br ou www.brazilianjournal.org.

Observe as normas de publicação, para facilitar e agilizar o trabalho de edição. 